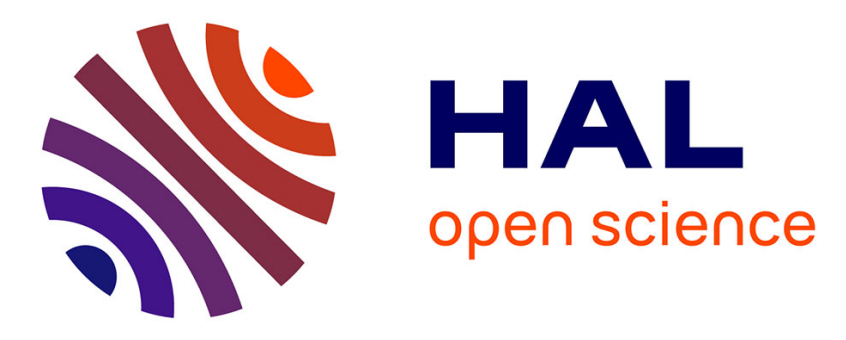

\title{
Experimental and numerical studies of the diluent influence (N2, Ar, He, Xe) on stable premixed methane flames in micro-combustion
}

\author{
Hugo Chouraqui, Guillaume Dayma, Guillaume Ribert, Fabien Halter, \\ Christian Chauveau, Philippe Dagaut
}

\section{To cite this version:}

Hugo Chouraqui, Guillaume Dayma, Guillaume Ribert, Fabien Halter, Christian Chauveau, et al.. Experimental and numerical studies of the diluent influence (N2, Ar, He, Xe) on stable premixed methane flames in micro-combustion. Proceedings of the Combustion Institute, 2021, 38 (4), pp.67536761. 10.1016/j.proci.2020.06.325 . hal-02937027

\section{HAL Id: hal-02937027 \\ https://hal.science/hal-02937027}

Submitted on 13 Apr 2021

HAL is a multi-disciplinary open access archive for the deposit and dissemination of scientific research documents, whether they are published or not. The documents may come from teaching and research institutions in France or abroad, or from public or private research centers.
L'archive ouverte pluridisciplinaire HAL, est destinée au dépôt et à la diffusion de documents scientifiques de niveau recherche, publiés ou non, émanant des établissements d'enseignement et de recherche français ou étrangers, des laboratoires publics ou privés. 


\title{
Experimental and numerical studies of the diluent influence $\left(\mathrm{N}_{2}, \mathrm{Ar}, \mathrm{He}, \mathrm{Xe}\right)$ on stable premixed methane flames in micro-combustion
}

\author{
Hugo Chouraqui ${ }^{\mathrm{a}, \mathrm{b}}$, Guillaume Dayma ${ }^{\mathrm{a}, \mathrm{b}, *}$, Guillaume Ribert ${ }^{\mathrm{c}, *}$, Fabien Halter ${ }^{\mathrm{a}, \mathrm{b}}$, \\ Christian Chauveau ${ }^{\mathrm{a}}$, Philippe Dagaut ${ }^{\mathrm{a}}$ \\ ${ }^{a}$ CNRS-INSIS, I.C.A.R.E., 1C, Avenue de la recherche scientifique, \\ 45071 Orléans cedex 2, France \\ ${ }^{b}$ University of Orleans, 1 rue de Chartres, 45067 Orléans cedex 2, France \\ ${ }^{c}$ CORIA - CNRS, Normandie Université, INSA de Rouen Normandie \\ 76000 Rouen, France
}

\begin{abstract}
This work focuses on the diluent influence on stable methane flames in a fused silica micro flow reactor (MFR). Experimental and numerical investigations are performed. The first part presents the method of performing experiments and extracting data from an MFR in order to increase the reliability of the communication of the results. Those methods are applied to premixed stoichiometric methane flames diluted by nitrogen, argon, helium and xenon. Methods to point out the influence of mixture thermodynamic and transport properties influence is presented. A numerical study of the influence of diluent on stable flames is also undertaken to support the experimental observations difficult to realize in such micro-devices. Keywords: Micro-combustion, FREI, Stable flames, Diluents
\end{abstract}

\footnotetext{
*Corresponding authors:

Email addresses: guillaume.dayma@cnrs-orleans.fr (Guillaume Dayma), guillaume.riberteinsa-rouen.fr(Guillaume Ribert)
} 


\section{- Corresponding author:}

- Last name: Ribert

- First name: Guillaume

- Mailing address:

CNRS-CORIA - INSA de Rouen,

Campus du Madrillet,

Avenue de l'Université,

76801 St-Etienne-du-Rouvray, France

- Phone number: +33(0)232959792

- Email: guillaume.ribert@insa-rouen.fr

- Colloquium 13: New Concepts

- Abstract: 110 words

- Article, total length: $5550=6 \times 900+2.2 \times 50 \mathrm{~mm}$ with the two-column method (LaTeX)

- Color figures: not applicable

\section{Introduction}

Portable power generation devices exploiting the high-density energy of hydrocarbon fuels have led to a growing interest in research in the field of microscale combustion [1]. Reactors used in micro combustion have an inner diameter that is typically smaller than the quenching diameter. At this scale, characteristic flame behaviors have been experimentally [2] observed such as flames with repetitive 
extinction and ignition (FREI), weak flames and stable flames. Previous studies investigated fuel/air mixtures [3-5] but since applications to microscale combustion are numerous, a deep understanding of flame behaviors in different environments is required. Therefore the present work focuses on the influence of different diluents on premixed stable $\mathrm{CH}_{4}$ flame to point out physico-chemical properties that have an impact on stable flames in microflow reactor (MFR). This problem is considered by the use of experimental and numerical methods since the study of a premixed flame propagating in a tube is actually a complicated process [6] resulting from a complex coupling between fluid dynamics, chemical kinetics, wall heat transfers, acoustics, etc. The way these processes are modeled leads to different flame shapes. For example, considering an adiabatic wall condition for the simulation of a flame propagating in a micro tube will yield a concave flame, but activating wall heat transfers produces a tulip flame [7, 8]. Similarly, a recent study has shown the strong impact that can have gravity on stationary laminar flame in micro-channels [9].

The purpose of this article is to better understand the propagation of flames in micro-systems with the presence of diluents. An attempt is made to identify the main parameters that play a role in the different flow regimes. The study of such flame is highly challenging since the strong flame-wall interaction implies that the flame takes a long time to stabilize in the MFR. The impact of this time is very important on experimental results and is a major issue of numerical studies. 


\section{Experimental methods}

\subsection{Experimental set-up}

The experimental set-up used in this study has been described earlier [3] and is shown in Figure 1. A cylindrical quartz micro-flow reactor (MFR) of $1.85 \mathrm{~mm}$ inner diameter, is externally heated by three $\mathrm{H}_{2} / \mathrm{O}_{2}$ micro blowtorches (Spirig blowtorches). This heating system induces a homogenous temperature distribution around the surface and a controlled temperature gradient along the tube, reducing heat losses and allowing the combustion in diameters smaller than the standard quenching diameter. An infrared camera (FLIR A655sc) continuously monitors the external temperature of the quartz tube. In this study, two different systems were used to determine the flame position in the reactor. Results for $\mathrm{CH}_{4} /$ air flames, taken from [3], $\mathrm{CH}_{4} / \mathrm{O}_{2} / \mathrm{Ar}$ and $\mathrm{CH}_{4} / \mathrm{O}_{2} / \mathrm{Xe}$ used a Princeton Instrument spectroscopy EMCCD camera (ProEm 1600). Results for diluents containing He used a Phantom v1611 camera coupled with a High-Speed IRO intensifier. The use of two different cameras is reputed to have no impact on the results. A 430 $\mathrm{nm}$ passband filter is used to detect the $\mathrm{CH}^{*}$ emission from the flame.

\subsection{Determination of stable flames characteristic point}

In microscale combustion, the low surface to volume ratio implies strong exchanges between the wall of the reactor, the flame and the environment. Hence it is important to wait for the equilibrium of the system to extract data from MFR experiments. The first step is to reach the thermal equilibrium of the MFR externally heated by the three blowtorches with the environment waiting for a stable temperature profile. With this method, the temperature gradient is controlled and reproducible. Then the mass flow rate of the premixed mixture $\mathrm{CH}_{4} /$ diluent cor- 

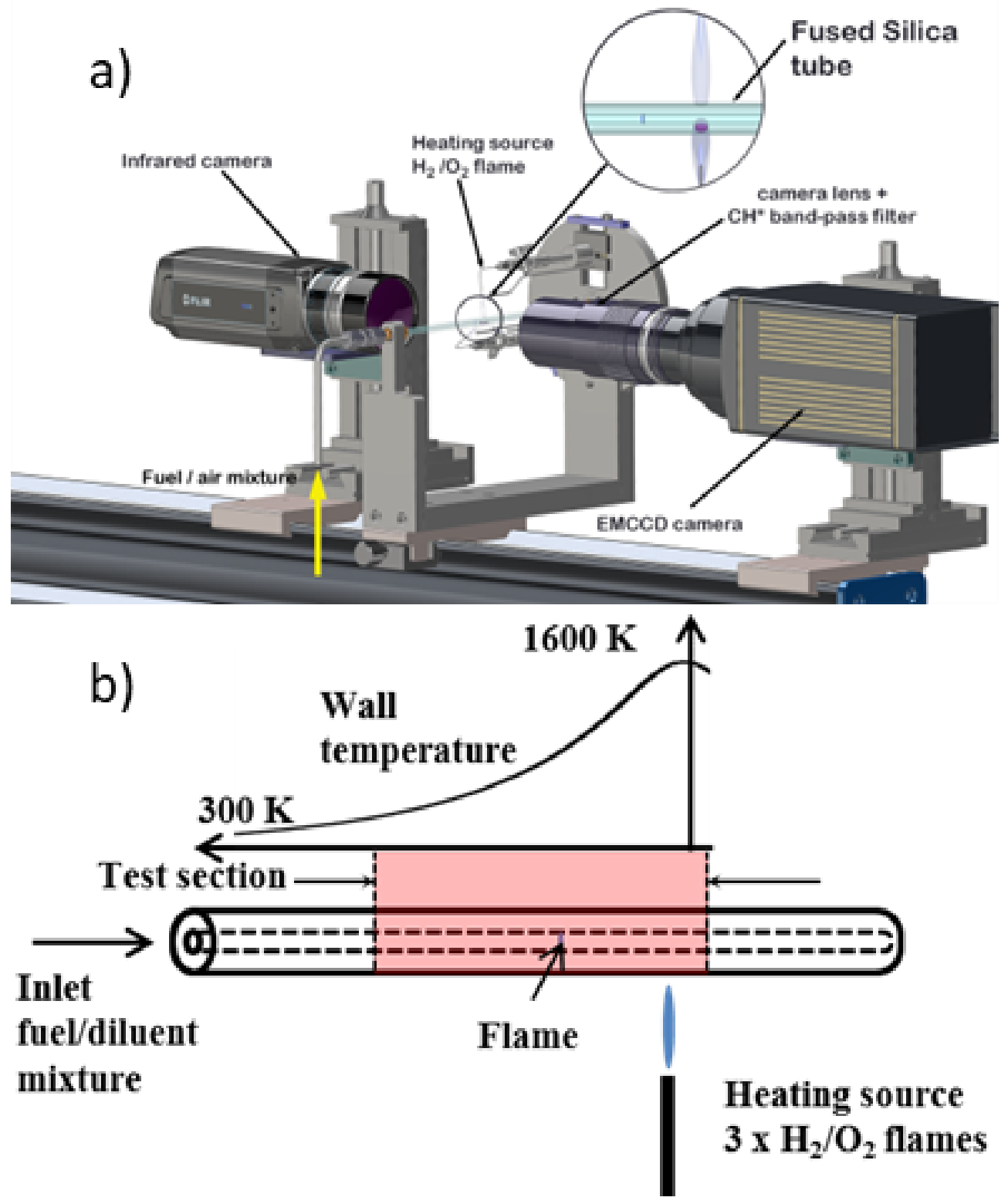

Figure 1: a) Schematic of the experimental set-up; b) Schematic of the temperature profile along the channel (test section represented in red has a length of $0.03 \mathrm{~m}$ ). 

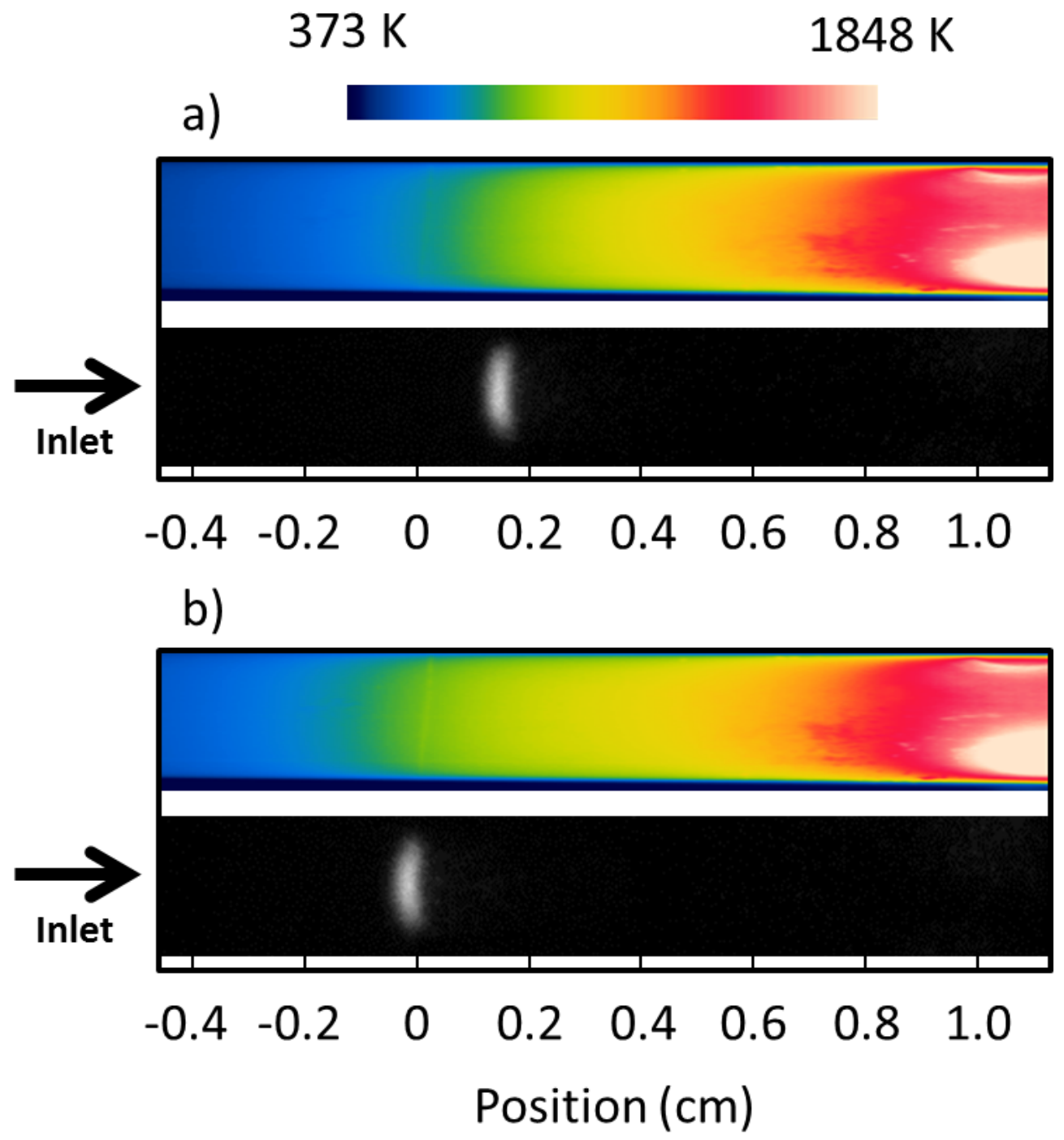

Figure 2: Comparison between the stable flame position in the MFR at the beginning of the experiment a) and after 5 minutes b) of a stoichiometric mixture of $\mathrm{CH}_{4}$ with the diluent $\mathrm{He} / \mathrm{O}_{2}$ with an inlet flow velocity of $1.4 \mathrm{~m} / \mathrm{s}$. Each image represent at the top the thermal image of the external temperature of the MFR and at the bottom an image of the stable flame taken with an intensified camera coupled with a $\mathrm{CH}^{*}$ band-pass filter. 
responding in this study of stable flames behavior is applied, followed by the autoignition of the mixture that occurs around the blowtorches. Then the flame front is stabilizing in a colder area of the MFR. Due to the high temperature of the flame compared to the wall temperature of the MFR, there is an increase of the wall temperature by conduction implying a preheating area of the fresh premixed gas. This preheat zone induces a displacement of the flame front toward a colder area of the MFR. This displacement of the flame front is very slow and can not be seen by naked eyes and can strongly influence experimental results on stable flames in MFR. The flame displacement is represented in Figure 2 where a) represents the flame a few seconds after the establishment of the premixed mixture in the MFR. Figure 2 b) represents it after the equilibrium reached several minutes after the a). In this study, all stable flames location in the MFR were established using this method. The time before reaching the complete stabilization of the flame has not been investigated in this study but strongly depends on the fluid properties and its velocity. It should be noted that all the results plotted in the Results and Discussion section represents the whole range of inlet mixture velocity leading to a stable flame behavior. Outside this inlet velocity range, either the flame becomes unstable (velocity too low), or the flame is blown out (velocity too strong).

\subsection{Determination of FREI characteristic points}

As described in [10], ignition in FREI occurs at the hot wall temperature region near blowtorches. Then the flame front propagates upstream toward fresh gases until it is finally quenched downstream in colder wall region. The previous experimental study [11], carried with the same experimental set-up, used the ignition and extinction location to characterize FREI. The extinction occurs when the 
signal-to-noise ratio of $\mathrm{CH}^{*}$ is too low to get the location of the flame. By definition, the location of this point strongly depends on the sensitivity of the measurement method and is difficult to compare with numerical studies. In this work, the maximum upstream location of the flame is used. At this point, the flame propagation speed becomes smaller than the local flow velocity, inducing little variations of flame position in the reactor which facilitates its spatial determination. Indeed, as can be seen from Fig. 3, the ignition of the mixture occurs downstream in the blowtorches area. Then the mixture propagates toward fresh gases and reaches a

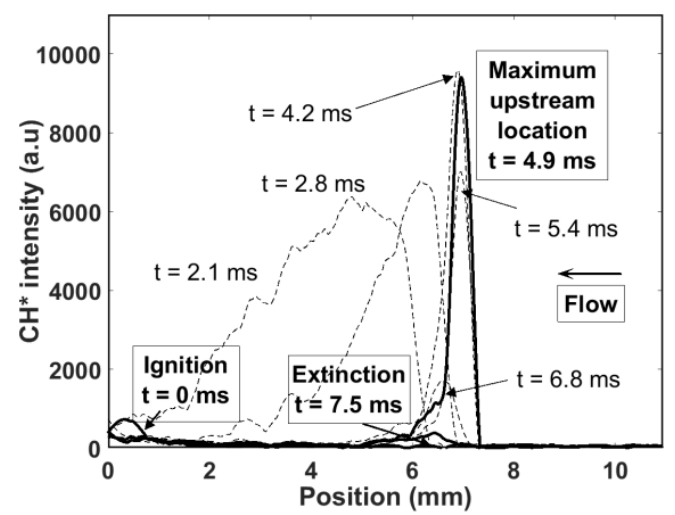

Figure 3: Temporal evolution of $\mathrm{CH}^{*}$ intensity obtained during FREI progression of premixed stoichiometric $\mathrm{CH}_{4} /$ air flame with an inlet flow velocity of $0.4 \mathrm{~m} / \mathrm{s}$ in a $1.85 \mathrm{~mm}$ inner diameter reactor [11].

maximum upstream location at $4.9 \mathrm{~ms}$. Then, due to energy losses at the wall, the flame propagation speed decreases and become smaller than the local flow velocity. It is worth noting that the maximum upstream location does not correspond to the maximum $\mathrm{CH}^{*}$ intensity recorded that occurs $4.2 \mathrm{~ms}$ after the ignition is detected. After reaching this turning point, the intensity continues to decrease and the flame front starts going downstream with decreasing signal intensity until reaching the extinction after $7.5 \mathrm{~ms}$. As previously explained, we can see that the 
low signal-to-noise ratio at the extinction makes measurement more difficult than at the turning point at $4.9 \mathrm{~ms}$. This is the reason why we will represent only the maximum upstream location of FREI in the MFR. The two characteristics points of FREI behavior which are ignition and maximum upstream location are experimentally extracted by doing the mean location in the MFR for each cycle of FREI.

\section{Results and discussion}

\subsection{Experimental approach}

In order to study the impact of diluents on stable flames in MFR, all experiments taken into account are for stoichiometric methane premixed flame, in the same tube with an inner diameter of $1.85 \mathrm{~mm}$ and with the same temperature gradient applied on the wall. The only parameters varying in this study are diluents used in the premixed flame and inlet velocities. The mole fraction of $\mathrm{O}_{2}$ is kept constant between each diluent in order to avoid chemical effects. Results for stoichiometric $\mathrm{CH}_{4}$ /air flames are extracted from previous experiments by Di Stazio et al. [3] whereas new results with other diluents were obtained during this work and are gathered in Table 1 .

Regardless of the diluent, the increase of inlet fresh gas velocity implies the displacement toward a hotter wall region of the stable flame location as can be observed from Figure 4 .

In Fig. 4, the smallest inlet mixture velocity leading to a stable flame behavior is $V_{m}=0.5 \mathrm{~m} / \mathrm{s}$ for a stoichiometric combustion with air. This flame is stabilized around a wall temperature of $T_{w}=1000 \mathrm{~K}$. If air is now diluted by $50 \%$ of helium, the minimal inlet velocity reaches $V_{m}=0.77 \mathrm{~m} / \mathrm{s}$, before jumping above $V_{m}=1.2 \mathrm{~m} / \mathrm{s}$ for $100 \%$ of helium. $V_{m}$ thus increases with the addition of helium in 


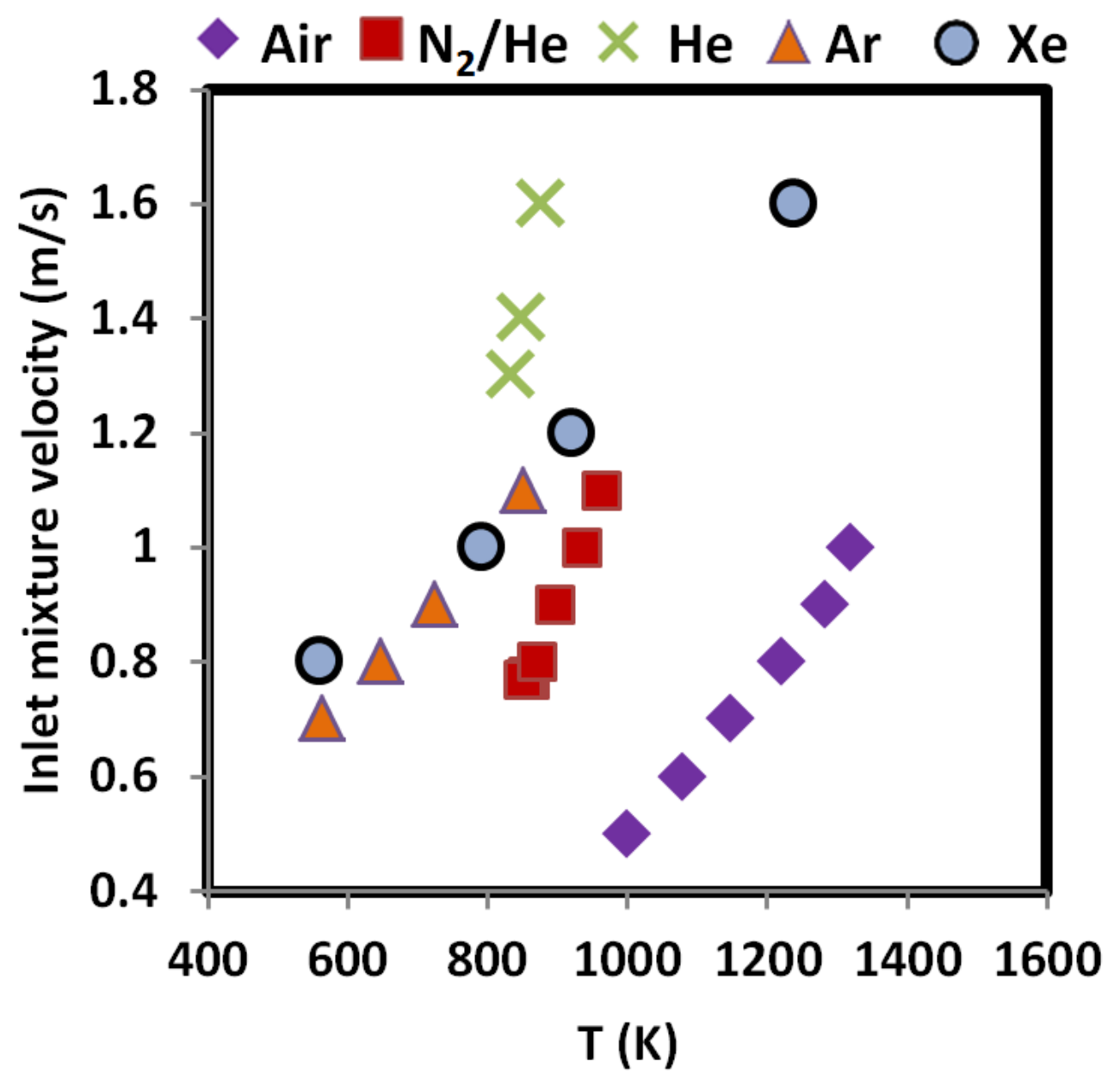

Figure 4: Temperature stabilization of stoichiometric $\mathrm{CH}_{4}$ flames as a function of mixture inlet mean velocities for different diluents

the diluent. In table 2 are reported the laminar burning velocity $\left(S_{L}\right)$ of the different studied cases for $\mathrm{CH}_{4}$ /diluents. In particular, it is observed for stoichiometric conditions that $S_{L}($ Air $)<S_{L}\left(N_{2}+H e\right)<S_{L}(H e)$. It means that if $V_{m}=0.5 \mathrm{~m} / \mathrm{s}$, diluted flames by helium can propagates toward the fresh gases and reach a zone of the MFR where the temperature of the wall is colder. These flames disappear and a FREI then appear. Obtaining a stable flame with helium as diluent requires 


\begin{tabular}{cccccc}
\hline Diluent & $\mathrm{O}_{2}$ & $\mathrm{~N}_{2}$ & $\mathrm{He}$ & $\mathrm{Ar}$ & $\mathrm{Xe}$ \\
\hline Air [11] & 21.0 & 79.0 & 0 & 0 & 0 \\
$\mathrm{~N}_{2} / \mathrm{He}$ & 21.2 & 39.6 & 39.2 & 0 & 0 \\
$\mathrm{He}$ & 21.7 & 0 & 78.3 & 0 & 0 \\
$\mathrm{Ar}$ & 21.6 & 0 & 0 & 78.4 & 0 \\
$\mathrm{Xe}$ & 21.0 & 0 & 0 & 0 & 79.0 \\
\hline
\end{tabular}

Table 1: Compositions of the diluents used in this study in mole fraction (\%).

to increase $V_{m}$. At $V_{m}=0.77 \mathrm{~m} / \mathrm{s}$, the $50 \%-50 \% \mathrm{~N}_{2}-\mathrm{He}$ flame is stabilized at $T_{w} \approx 860 \mathrm{~K}$. At $V_{m}=1.2 \mathrm{~m} / \mathrm{s}$, the $100 \%$ He flame is stabilized at $T_{w} \approx 840 \mathrm{~K}$. With the addition of helium, the flame can then propagate toward fresh gases at

\begin{tabular}{|c|c|c|c|c|c|}
\hline Diluent & $S_{L}(\mathrm{~m} / \mathrm{s})$ & $T_{a d}(\mathrm{~K})$ & $\begin{array}{c}\lambda\left(10^{-2}\right. \\
\left.\mathrm{W} \cdot \mathrm{m}^{-1} \cdot \mathrm{K}^{-1}\right)\end{array}$ & 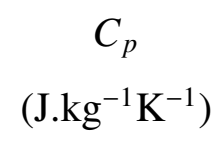 & $\begin{array}{l}\mathcal{D}\left(10^{-5}\right. \\
\left.\mathrm{m}^{2} \cdot \mathrm{s}^{-1}\right)\end{array}$ \\
\hline Air [1] & 0.37 & 2225 & 2.65 & 1075 & 2.34 \\
\hline $\mathrm{N}_{2} / \mathrm{He}$ & 0.72 & 2377 & 5.48 & 1401 & 3.11 \\
\hline $\mathrm{He}$ & 1.28 & 2541 & 9.08 & 2240 & 4.54 \\
\hline Ar & 0.77 & 2538 & 2.03 & 661 & 2.32 \\
\hline $\mathrm{Xe}$ & 0.57 & 2521 & 0.97 & 235 & 1.76 \\
\hline
\end{tabular}

Table 2: Properties of a stoichiometric mixture $\mathrm{CH}_{4} /$ diluent: laminar burning velocity $\left(S_{L}\right)$, adiabatic flame temperature $\left(T_{a d}\right)$, Thermal conductivity $(\lambda)$, Specific heat capacity $\left(C_{p}\right)$ and $\mathrm{CH}_{4}$ mass diffusivity (D).

higher inlet mixture velocity. This correlation between the ability of the flame front to propagate toward fresh mixture and the laminar flame speed can be extended to flame diluted with argon and xenon. Indeed the laminar flame speed of 
stoichiometric premixed methane flame diluted with $\mathrm{N}_{2} / \mathrm{He}, \mathrm{He}, \mathrm{Ar}$ and $\mathrm{Xe}$ are all above $S_{L}\left(\right.$ Air) (see Table 2). For argon and xenon, $V_{m}=0.7 \mathrm{~m} / \mathrm{s}$ and $0.8 \mathrm{~m} / \mathrm{s}$, respectively, for a wall temperature of $T_{w} \approx 580 \mathrm{~K}$ meaning that such flames lose less energy than flames with air or helium. This is explained by the fact that the transport $(\lambda, \mathcal{D})$ and thermodynamic $\left(C_{p}\right)$ properties are all lower with argon and xenon than with helium, for example, whereas the flame temperature of each is of the same order of magnitude $(\approx 2530 \mathrm{~K})$. The thermal exchange between the flame and the wall is then weaker with $\mathrm{O}_{2} / \mathrm{Ar}$ and $\mathrm{O}_{2} / \mathrm{Xe}$ diluent than with $\mathrm{O}_{2} / \mathrm{He}$. As already stated above, diluted flames with air or helium exhibit a FREI behavior if the inlet mixture velocity is smaller than the minimal speed, $V_{m}$. Such a process can be summarized as follow: the high thermal conductivity $(\lambda)$ of the fluid leads to high heat losses at the wall of the MFR when the flame propagates toward fresh gases, resulting in a quenching mechanism. However, in the case of a dilution with xenon (also argon), such thermal exchange between the flame and the wall is reduced since $\lambda$ is much lower than for the other diluents. Wall heat losses become minimal making a quenching mechanism, the starting point of the FREI, impossible. The diameter of the tube used in this study may therefore simply be too wide to observe the behavior of FREI with xenon and argon as diluents. Indeed as it is represented in Fig. 5, flames diluted with Xe and Ar in a MFR with an inner diameter of $1.00 \mathrm{~mm}$ exhibits a FREI behavior with an inlet mixture velocity respectively bellow $0.6 \mathrm{~m} / \mathrm{s}$ and $0.9 \mathrm{~m} / \mathrm{s}$. Therefore, recording the displacement of the flame in the case of dilution with xenon and argon, as in Fig. 2, requires a long experimentation time in order to reach thermal equilibrium in the MFR, i.e. between the flame, the quartz tube and the external environment. If not, the flame slowly heats the tube which releases energy upstream, by thermal conduction in 
the tube. The consequence is a flame propagation upstream as in the phenomenon of flashback.

\subsection{Numerical approach}

Simulating such configuration is a real challenge since the configuration is highly multi-physics. It is then convenient to reduce the problem to two dimensions as in [7-9]. $\mathrm{A} \mathrm{CH}_{4}$ /diluent mixture is therefore injected in a planar channel (height: $h=1.85 \mathrm{~mm}$ as in the experiment) whose walls are heated by blowtorches. The temperature profile imposed by these torches is given in Fig. 6 and is extracted from experimental measurements. The temperature of the mixture is $300 \mathrm{~K}$ and pressure is one atmosphere. The domain of computation ranges from $51 \mathrm{~mm}$ to $+15 \mathrm{~mm}$ in order to have inlet and outlet conditions that are not strongly influenced by torch heat. Only half of the domain is simulated since no gravity effect are considered. A Poiseuille velocity profile is imposed at the inlet. The bulk velocity at the inlet is $0.9 \mathrm{~m} / \mathrm{s}$ in order to potentially find a stable flame for all diluents. Indeed, the numerical configuration, even if it is close to the experimental one, presents significant differences ( $3 \mathrm{D}$ vs $2 \mathrm{D}$, no transfer of heat inside the walls of the tube) which make a quantitative comparison impossible. However, the dynamics of the flame should be recovered as in the study [9] in which the gravity played a major role in the flame asymmetry.

The sketch of the numerical configuration is shown in Fig. 7. A regular mesh composed of squares of $\Delta x$ side is used. The mesh resolution is $\Delta x=12.5 \mu \mathrm{m}$. The $\mathrm{CH}_{4}$ /diluents decomposition is described with the chemistry used in [7, 12] that contains 16 reacting species plus diluents and 53 elementary reactions. The complete system of conservation equations of species mass fractions, momentum and total sensible energy are solved in their fully compressible form over the 
structured mesh in a finite volume formulation resorting to a skew-symmetric-like scheme for the convective fluxes [13] and to a fourth-order centred scheme for the viscous and diffusive fluxes. Time is advanced with a fourth order RungeKutta scheme. One-dimensional Navier-Stokes characteristic boundary conditions (NSCBC) are applied [14]. The skew-symmetric centered scheme is nondissipative and it is completed by an addition of second and fourth-order artificial dissipation terms [15-17]. Such a strategy has been recently used with success for the simulation of laminar channel flows [7--9] through our home-made code SiTCom-B [18-22], which will be used for this study.

The results of simulations is provided in Fig. 8 for a premixed flame of methane with $\mathrm{O}_{2}+\mathrm{N}_{2}$ (air), $\mathrm{O}_{2}+\mathrm{Ar}$ and $\mathrm{O}_{2}+\mathrm{He}$. The field of temperature is provided along with the heat release rate in order to define the position of the resulting stable flame. Xenon flame was also simulated but it exhibited a flashback type behavior. Its flame structure resembled that of the helium flame as in Fig. 8 (bottom), i.e. with a very pronounced concave shape. This shape of flame is observed numerically when the wall temperature condition does not exceed a limit value, which is close to $900 \mathrm{~K}$ in the case of combustion of methane in the air [7]. This consideration is in agreement with the experimental observations of Fig. 2 even if the bulk velocity is different. Beyond this limit value, a tulip flame appears as observed in the simulations with air and argon. Behind the flame front with $\mathrm{He}$, the highest temperature of burned gases $\left(T_{b g}\right)$ is $2120 \mathrm{~K}$ which is $420 \mathrm{~K}$ less than its adiabatic flame temperature. Similarly, $T_{b g}(A r)=2400 \mathrm{~K}$ (140 K less) and $T_{b g}($ Air $)=2106 \mathrm{~K}(120 \mathrm{~K}$ less $)$. The temperature conditions of the wall therefore have a strong impact on the behavior and shape of the flame. Nevertheless, the numerical simulation made it possible to find the good order of stabilization of 
the three flames. The fastest propagating flame, the helium flame, is farthest from torches. Then comes the flame with argon, then in the air.

Even if a direct comparison with the experimental measurements is not possible, as explained above, it will nevertheless allow to validate the impact of the diluent on the dynamics of the flame. The location of stable flames is then compared in Tab. 3 to the one obtained experimentally, in terms in wall temperature (thanks to Fig. 6). A stable flame with xenon is experimentally observed unlike the simula-

\begin{tabular}{ccccc}
\hline Diluent & $\mathrm{N}_{2}$ & $\mathrm{He}$ & $\mathrm{Ar}$ & $\mathrm{Xe}$ \\
\hline$T_{E x p}(\mathrm{~K})$ & 1300 & {$[-]$} & 750 & 680 \\
$T_{\text {Num }}(\mathrm{K})$ & 1335 & 880 & 1105 & {$[-]$} \\
\hline
\end{tabular}

Table 3: Value of the wall temperature where the stable flame is located. $T_{E x p}$ comes from experimental data (Fig. 4) and $T_{\text {Num }}$ from numerical results. $T_{\text {Num }}$ is given with $\pm 15 \mathrm{~K}$.

tion that shows a flashback. The methane flame with air is pretty well recovered by simulations with a difference around $30 \mathrm{~K}$ despite a 2D approach. A stable flame was found by simulation in the case of $100 \%$ helium dilution, whereas it does not exist experimentally. However the value of the wall temperature $(\approx 880 \mathrm{~K})$ is near the limit value obtain by the experiments ( $850 \mathrm{~K}$ in Fig. 4). Finally, the $\mathrm{CH}_{4}$ flame diluted with argon is stable in both approaches, but is not in the same place. Such a disparity can be explained by the kinetics used to simulate the different flames. Indeed, a reduced mechanism of GRI1.2 [23] was used for this study. This reduced scheme has been optimized [12] to comply with the laminar premixed stoichiometric $\mathrm{CH}_{4}$ /air flames, and it has thus again yielded good results here (Tab. 3). However, for dilution cases, species such as argon, helium or xenon have simply been added to the reduced mechanism already optimized. For a better prediction 
of the flame stabilization, a new optimization step on diluted flames described by a detailed chemistry, validated for these large dilutions, is then compulsory.

\section{Conclusion}

Experiments were performed with premixed stoichiometric methane flames with five diluents. A strong impact of the diluent on stable flames behavior was observed. For example, in the case of low velocity flows, the addition of helium to a methane/air flame causes its extinction. In addition, the use of $100 \%$ xenon or helium instead of nitrogen provides a very hot flame propagating at a speed twice that achievable with air. As expected in MFR due to the small surface to volume ratio, the thermal conductivity of the mixture plays a significant role in stable flames locations. In the case of the two smallest conductivity mixture (Xe and Ar cases), a decrease in inlet velocity could lead to a flashback or a FREI behavior respectively with a $1.85 \mathrm{~mm}$ and $1.00 \mathrm{~mm}$ inner diameter MFR. Finally, numerical simulations have shown a great potential of prediction for such systems, the key point remaining the validity of the kinetic scheme capable of describing these large dilutions.

\section{Acknowledgments}

The authors thank the Ministry of Research in Higher Education (MESRI) for a PhD grant. Support from the CAPRYSSES project (ANR-11-LABEX-00601) funded by ANR through the PIA (Programme d'Investissement d'Avenir) is gratefully acknowledged. 


\section{References}

[1] X. Kang, A. Veeraragavan, Experimental demonstration of a novel approach to increase power conversion potential of a hydrocarbon fuelled, portable, thermophotovoltaic system, Energy Conversion and Management 133 (2017) 127-137.

[2] K. Maruta, J. K. Parc, K. C. Oh, T. Fujimori, S. S. Minaev, R. V. Fursenko, Characteristics of Microscale Combustion in a Narrow Heated Channel, Combustion, Explosion and Shock Waves 40 (5) (2004) 516-523.

[3] A. Di Stazio, C. Chauveau, G. Dayma, P. Dagaut, Combustion in microchannels with a controlled temperature gradient, Experimental Thermal and Fluid Science 73 (2016) 79-86.

[4] Y. Kizaki, H. Nakamura, T. Tezuka, S. Hasegawa, K. Maruta, Effect of radical quenching on $\mathrm{CH} 4 /$ air flames in a micro flow reactor with a controlled temperature profile, Proceedings of the Combustion Institute 35 (3) (2015) 3389-3396.

[5] V. R. Kishore, S. Minaev, M. Akram, S. Kumar, Dynamics of premixed methane/air mixtures in a heated microchannel with different wall temperature gradients, RSC Advances 7 (4) (2017) 2066-2073.

[6] H. Xiao, R. Houim, E. Oran, Formation and evolution of distorted tulip flames, Combust. Flame 162 (2017) 4084-4101.

[7] K. Bioche, L. Vervisch, G. Ribert, Premixed flame-wall interaction in a narrow channel: Impact of wall thermal conductivity and heat losses, J. Fluid Mech. 856 (2018) 5-35. 
[8] K. Bioche, G. Ribert, L. Vervisch, Simulating upstream flame propagation in a narrow channel after wall preheating: Flame analysis and chemistry reduction strategy, Combust. Flame 200 (2019) 219-231.

[9] K. Bioche, A. Pieyre, G. Ribert, F. Richecoeur, L. Vervisch, The role of gravity in the asymmetry of flames in narrow combustion chambers, Combust. Flame 203 (2019) 238-246.

[10] H. Nakamura, A. Fan, S. Minaev, E. Sereshchenko, R. Fursenko, Y. Tsuboi, K. Maruta, Bifurcations and negative propagation speeds of methane/air premixed flames with repetitive extinction and ignition in a heated microchannel, Combustion and Flame 159 (4) (2012) 1631-1643.

[11] A. Di Stazio, C. Chauveau, G. Dayma, P. Dagaut, Oscillating flames in micro-combustion, Combustion and Flame 167 (Supplement C) (2016) 392394.

[12] N. Jaouen, L. Vervisch, P. Domingo, G. Ribert, Automatic reduction and optimisation of chemistry for turbulent combustion modeling: Impact of the canonical problem, Combust. Flame 175 (2017) 60-79.

[13] F. Ducros, V. Ferrand, F. Nicoud, C. Weber, D. Darracq, C. Gacherieu, T. Poinsot, Large-eddy simulation of the shock/turbulence interaction, J. Comput. Phys. 152 (2) (1999) 517-549.

[14] T. J. Poinsot, S. K. Lele, Boundary conditions for direct simulations of compressible viscous flows, J. Comput. Phys. 101 (1) (1992) 104-129. 
[15] A. Jameson, W. Schmidt, E. Turkel, Numerical solution of the euler equations by finite volume methods using runge kutta time stepping schemes, in: 14th Fluid and Plasma Dynamics Conference, 1981, p. 1259.

[16] R. Swanson, E. Turkel, On central-difference and upwind schemes, J. Comput. Phys. 101 (2) (1992) 292-306.

[17] S. Tatsumi, L. Martinelli, A. Jameson, Flux-limited schemes for the compressible Navier-Stokes equations, AIAA Journal 33 (2) (1995) 252-261.

[18] U. Guven, G. Ribert, Large-eddy simulation of supersonic h2/o2 combustion: application to a rocket-like igniter, J. Propul. Power 34 (2018) 291 307.

[19] U. Guven, G. Ribert, Impact of non-ideal transport modeling on supercritical flow simulation, Proc. Combust. Inst. 37 (2019) 3255 - 3262.

[20] G. Ribert, P. Domingo, L. Vervisch, Analysis of sub-grid scale modeling of the ideal-gas equation of state in hydrogen-oxygen premixed flames, Proc. Combust. Inst. 37 (2019) $2345-2351$.

[21] B. Duboc, G. Ribert, P. Domingo, Hybrid transported-tabulated chemistry for partially premixed combustion, Computers Fluids 179 (2019) 206 - 227.

[22] B. Duboc, G. Ribert, P. Domingo, Evaluation of chemistry models on methane/air edge flame simulation, Proc. Combust. Inst. 37 (2019) 16911698.

[23] M. Frenklach, H. Wang, C.-L. Yu, M. Goldenberg, C. T. Bowman, R. K. Hanson, D. F. Davidson, E. J. Chang, G. P. Smith, D. M. Golden, W. C. Gar- 
diner, V. Lissianski, Gri-mech-an Optimized Detailed Chemical Reaction Mechanism for Methane Combustion, Tech. rep., Gas Research Institute, Chicago, IL, report No. GRI-95/0058 (1995). 

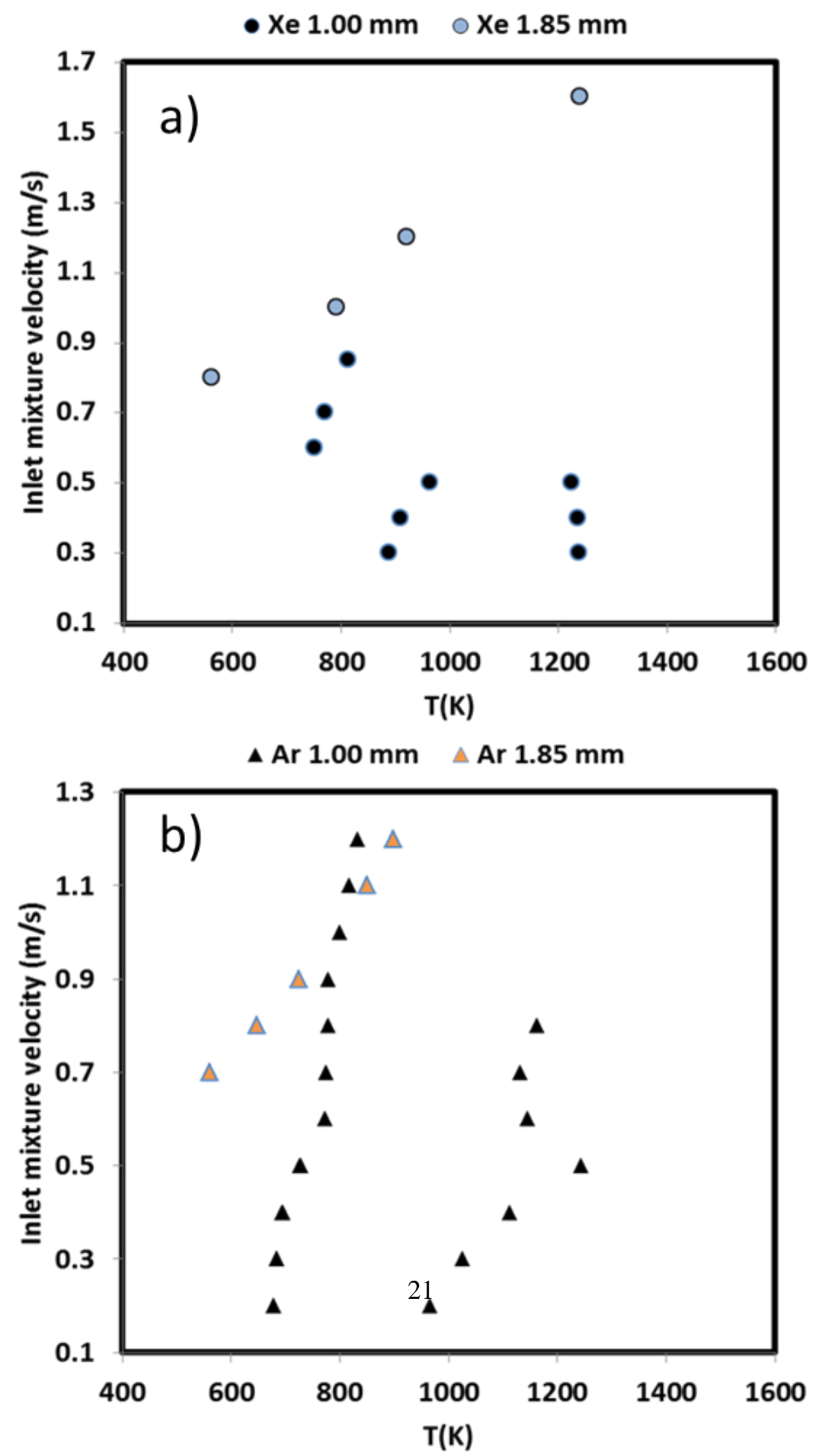

Figure 5: Stable flames and FREI characteristic points location of stoichiometric $\mathrm{CH}_{4}$ flames as a 


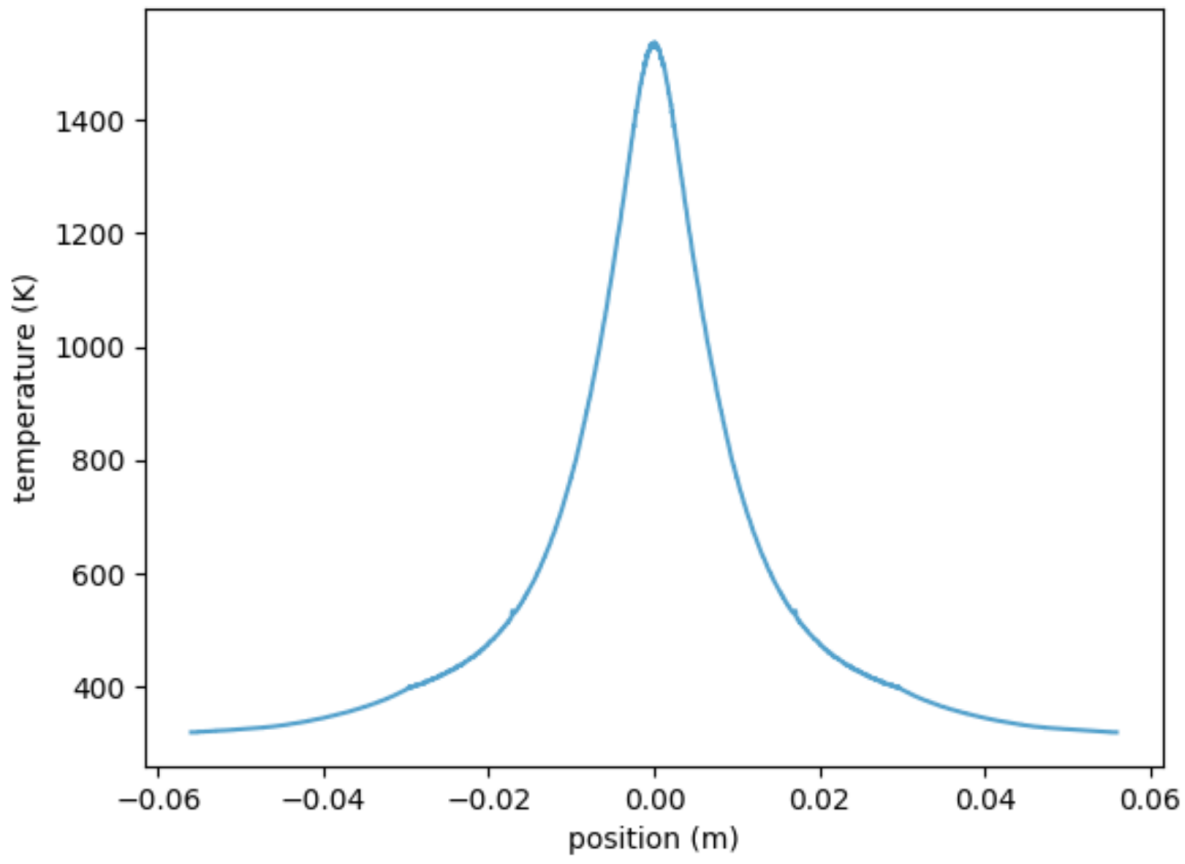

Figure 6: Temperature profile at the wall representing the temperature evolution imposed by the blowtorches in the experiment.

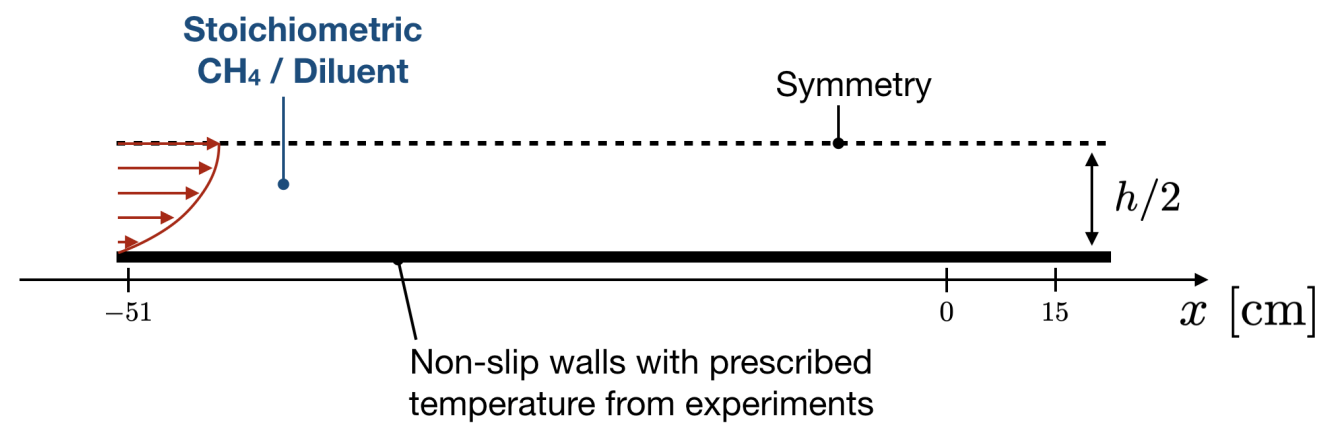

Figure 7: Configuration of the 2D channel. 

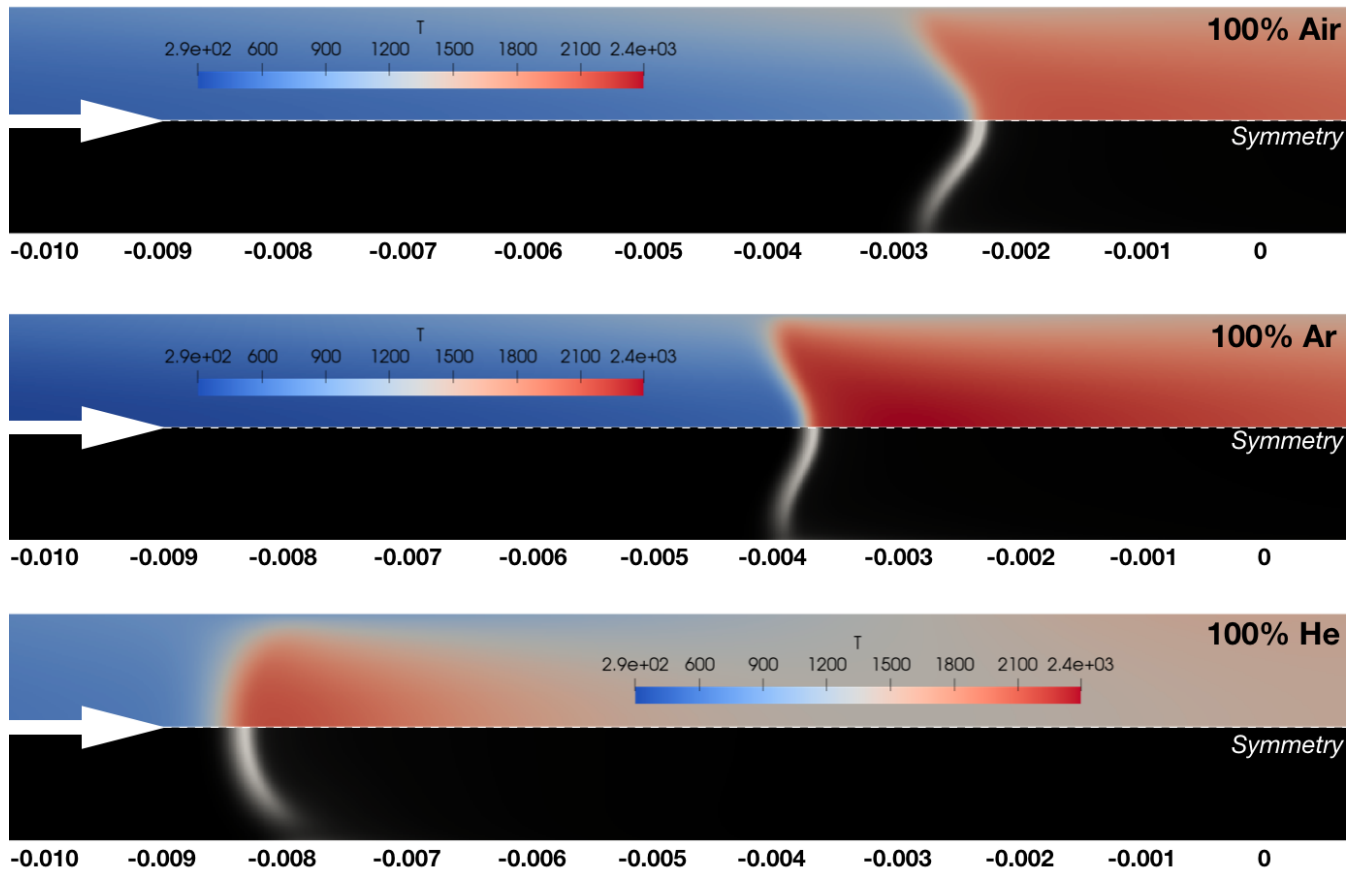

Figure 8: Numerical simulation of a premixed flame of methane with $\mathrm{O}_{2}+\mathrm{N}_{2}$ (top), $\mathrm{O}_{2}+\operatorname{Ar}$ (middle) and, $\mathrm{O}_{2}+\mathrm{He}$ (bottom). In black: the heat release rate that define the flame position. In color, the temperature field. Abscissa in meters. 